Pakistan Journal of Education

Vol.36, No.3, 2019, 119-143

\title{
Employing James Gee's Analytic Lens for Identity to Investigate Teacher Identity Development
}

\author{
Shagufta Moghal ${ }^{*}$ \\ Asma Shahid Kazi** \\ Fakhra Aziz***
}

\begin{abstract}
The current article is an exploration of the construction and development of teacher identities at the tertiary level in Pakistan. Identity is the sense of who one is as a professional, and it is becoming evident that it is important for teachers at all levels to develop a clear sense of identity which is at harmony with their inner sense of self and personal values. There is evidence that successful identity construction leads to better practices and high level of commitment to the profession. The researcher adopted a constructivist stance for the investigation of identity and used data triangulation by using life histories, semi-structured interviews (based on the James Gee's Lens for Identity) and fieldnotes as the sources of data. Six participants from urban tertiary institutions in various cities of Pakistan were selected and interviewed. The gathered data was analyzed iteratively through coding and contrastive analysis and highlighted the similarities and disparities of the various perspectives of identity; it was discovered that the participants had a better awareness and acceptance of their nature identity, whereas the institutional and discursive identities were the ones that posed conflict for them. The researcher also found that affinity identity was the weakest link in the Gee lens for teachers of Pakistan.
\end{abstract}

Keywords: identity construction, tertiary education, James Gee's Lens for identity, teacher development, semi structured interviews

* Department of Professional Studies, Institute of Education, Lahore College for Women University.Email: shagufta.moghal@lcwu.edu.pk

** Department of Professional Studies, Institute of Education, Lahore College for Women University.Email: asma.kazi@lcwu.edu.pk

** Institute of Education, Lahore College for Women University.

Email:fakhraaziz@hotmail.com 


\section{Introduction}

Over the last 2 decades conversations and dialogues about identity perception and identity development, particularly related to teachers, have become a part of the academic discourse (Sachs, 2005; Freese, 2006; Olsen, 2015). Olsen (2015) propounds that to reform and improve the education process, "identity is a more useful analytic than teacher 'knowledge', and that 'teacher identity development'.. is more useful than the antiquated 'teacher learning"' (p. 6). One of the problems with teacher education programs and courses is that they usually don't consider the prior knowledge and beliefs of teachers, instead "approach the task of teacher socialization and development as though the beginner were a tabula rasa" (Bullough 1991, p. 43).

In reality, novice teachers enter the profession with a set of beliefs and notions formed by being a part of the education system, one way or the other for more than a decade (Anhorn, 2008); these preconceived beliefs may be idealistic or realistic, but often do not accurately encompass the complexity of the profession. Murshidi, Konting, Elias, and Fooi also support this view, saying that "when beginning teachers enter the teaching force, they often encounter a reality shock as they confront the complexity of the teaching task. The reality of the actual teaching situation sometimes differs so much from what the beginners were expecting" (2006, p. 266). Melnick \& Meister (2008) present a reason for this shock by saying that the visualization, expectations and idea about the profession which teachers have initially, contrasts with what realities they face.

Many researchers have represented this phenomenon as a "sink or swim" scenario (Hill, 2004; Lundeen, 2004; Street, 2004; Howe, 2006; Cobold, 2007). Featherstone (1993) also regards the early teaching experience as a time of "struggle to understand and change the self", proposing that the "complex and personal learning" of beginning teachers should be given due attention by paying attention to how the teacher professional identity is constructed (p. 94). This is especially relevant as, teachers are often motivated and enthusiastic towards their profession initially, but nearly $33 \%$ teachers leave their jobs within the first three years (Roulston, Legette, and Womack, 2005, p. 70).

Although many different conceptions and understandings of identity have surfaced, no single comprehensive definition of identity has been agreed upon. For Beijaard identity is "who or what someone is, the various meanings people can attach to themselves, or the meanings 
attributed by others" (1995, p. 281). Identity is not developed or formed in isolation, it is deeply seated or rooted in the situation or context where the experience initiates and exists; Sachs (2005) explains that the context is the backdrop or the basis for the meanings one ascribes to a specific experience or situation or constructs an understanding of what that experience means for oneself.

According to the way one constructs or reacts to a certain situation or experience gives a hint to what "kind of person" one is (Gee, 2000 , p. 101). He has put forth an analytic lens which examines identity from four different perspectives. This research paper aims to utilize and adapt the perspectives proposed by James Gee, into creating a tool to investigate and conceptualize teacher identity development and construction in tertiary teachers in Pakistan.

\section{Literature Review}

\section{Identity and Self Concept}

In the multiple definitions of identity, the notion of self-concept is common. Gecas (1985) supports this by saying that identity "gives structure and content to the self-concept and anchors the self to social systems" (p. 739). A common definition of 'self-concept' sums it up as "an organized summary of information, rooted in observable facts concerning oneself, which includes such aspects as traits of character, values, social roles, interests, physical characteristics and personal history" (Bergner \& Holmes, 2000, p. 36). Based on this definition, it is possible to distinguish between a 'personal self' and a 'professional self'. The personal self would be about all the traits, roles and responsibilities one performed; while the professional self would be about the professional roles, responsibilities and positions one would assume.

Although, theoretically the two identities are distinct, they are interlinked and overlapping (Nias, 1982). If there is incongruence or inconsistency between the personal and professional identities for long stretches of time, it causes friction within the individual teacher. To prevent such friction, educators turn their attention to the professional identity formation of teachers to better understand how successful teachers negotiate between the professional and personal self.

Flores and Day conducted a study on beginning teachers' experiences and identity which showed that in the face of disillusionment and frustration, the participants began to live a story of 'strategic compliance' (2006, p. 229). This strategic compliance allowed the participants to conform to their institutional standards and goals. This 
also enabled them to fit in and avoid friction when their personal and professional values came in conflict the professional expectations.

\section{Teacher Identity}

Teacher identity is a dynamic and ever-changing phenomenon, which is influenced by internal factors, such as emotions and a range of external experiences, such as life experience (Flores \& Day, 2006, p. 226). Sachs brings attention to the two-way negotiation between an individual's experiences and one's meaning making processes of those experiences. In the case of teachers, Sachs proposes that identity "provides a framework for teachers to construct their own ideas of "how to be", "how to act" and "how to understand" their work and their place in society" (2005, p. 15).

From another perspective, according to Day, Stobart, Sammons and Kington (2006), identity is developed because of the interlink and interactions between various factors of identity, which may be personal, professional and situational factors. The context or the environment of the institution or the school plays an important role in shaping these factors. One can only become aware about which of these factors is dominant or significant by looking at the life stories or the narratives of the individual's life (Kerby 1991; Volkmann \& Anderson, 1998).Hence, engaging in reflection through narratives is crucial for development of teacher identity and also provides an insight into how teacher identity is formed.

\section{The Underpinnings of Teacher Identity Formation}

Sachs proclaims that the process of identity development or formation is not very simple; it involves the (trans)formation or reconstruction of the teacher's identity, which as a process is "open, negotiated and shifting" (2005, p. 6). Davis, Sumara and Luce-Kapler proposed the "we become what we do" view of teacher identity formation which suggests that teacher identity is shaped by "teaching practices" $(2000$, p. 4).

The managerial view of teaching and teaching identity formation focuses on predefined and institutionalized teacher roles, expectations and idealistic standards. Dillabough (1999) mentions that such standards encourage in giving less importance to the private sphere of the individual teacher and subjugates their aims and identity to that of the system and the institution. According to Weeks, forming an identity means identification of commonalities with a particular group; "it is 
about belonging" (1990, p. 98) and knowing what differentiates one from the others. This makes a person an active agent in the ongoing and dynamic process of identity formation. This view is supported by the constructivist view of teacher identity, which sees identity as fluid and contextual, changing and evolving according to the many influences it undergoes; although the individual may or may not be conscious of this construction at the time (Graham and Phelps, 2003).

\section{James Gee's Analytic Lens for Identity}

James Gee has presented an analytic lens for examining identity from different perspectives. He defined identity in a more holistic manner, by saying that identity is how different individuals are "perceived as different 'kinds' of person in their given contexts" (2000, p. 3). This "kind of person" refers to one's identity. Gee focused on four distinct aspects or perspectives of Identity: The Nature-Identity, the Institution-Identity, the Discourse-Identity and the Affinity-Identity (Gee, 2000, p. 3). Gee was of the opinion that these perspectives "are four ways to formulate questions about how identity is functioning for a specific person...in a given context or across a set of different contexts" (Gee, 2000, p. 4).

According to Gee (2000), identity is not a permanent, fixed or stagnant concept; it is constantly changing and is very dynamic. In addition, a person may assume multiple identities based on the various roles $\mathrm{s} / \mathrm{he}$ has to play in society. The perspectives are presented concisely in Table 1.

Table 1

Four ways to view identity

\begin{tabular}{|c|c|c|c|c|}
\hline Perspective & Description & Process & Power & Source of Power \\
\hline Nature-Identity & A state & $\begin{array}{l}\text { Developed } \\
\text { from }\end{array}$ & Forces & In nature/Biological \\
\hline $\begin{array}{l}\text { Institution- } \\
\text { Identity }\end{array}$ & A position & Authorized by & Authorities & Within institutions \\
\hline $\begin{array}{l}\text { Discourse- } \\
\text { Identity }\end{array}$ & $\begin{array}{l}\text { An individual } \\
\text { trait }\end{array}$ & Recognized in & $\begin{array}{l}\text { The discourse/ } \\
\text { dialogue }\end{array}$ & $\begin{array}{l}\text { Of/with 'rational' } \\
\text { individuals }\end{array}$ \\
\hline $\begin{array}{l}\text { Affinity- } \\
\text { Identity }\end{array}$ & Experiences & Shared in & The practice & Of affinity groups \\
\hline
\end{tabular}

Adapted from "Identity as an analytic lens for research" (Gee, 2000).

As shown in the above table, according to the Nature perspective (N-Identities), identity is seen as "a state that I am in, not anything that I have done or accomplished" (Gee, 2000, p. 101). In this state the source of power is nature, something outside the individual's control and the 
control of the society. The process through which this identity is established is 'development' of a natural trait or ability. In addition, Gee explained that N-Identities "must always gain their force as identities through the work of institutions, discourse and dialogue, or affinity groups" (2000, p. 102).

The second is the Institutional perspective (I-Identities), where the identity is derived from some "position". Gee writes that "the process through which this power works is authorization; that is, laws, rules, traditions, or principles of various sorts allow the authorities to "author" the position" (2000, p. 102). There are certain roles and responsibilities associated with such positions. The institutions make sure that the person who has the I-identity is recognized and is a representative of that institution and is seen and perceived in a certain way. There is a continuum on which I-identities may be plotted, according to how actively or passively the individual seeks the position or the role; it may be a "vocation" or a "calling", if the person seeks the position; on the other hand, if the identity is ascribed (the label given), it may seem as an "imposition" (Gee, 2000, p. 103).

In the third perspective of identity, the discursive perspective (DIdentities), the "source of ... 'power' that determines it ... is the discourse or dialogue of other people... not nature or an institution, but "rational individuals" (Gee, 2000, p.103). This means that rational individuals recognize this identity or individual trait in a certain person and acknowledge it in discourse; no law, rule, ritual or sanction is needed otherwise. Additionally, these individual traits cannot exist alone or in isolation; they need some context or environmental factors in which to manifest and appear. Gee further explains that:

"D-Identities can be placed on a continuum in terms of how active or passive one is in "recruiting" them, that is, in terms of how much such identities can be viewed as merely ascribed to a person versus an active achievement or accomplishment of that person" (2000, p. 104).

It should be further elaborated that the discourse and dialogue with other individuals sustains and strengthens I-identities; in certain cases, institutions provide their people and employees with opportunities and interactions where such identities are developed and reinforced. In this way, it may be surmised that D-Identities may support and strengthen I- Identities.

The final perspective presented by Gee is of Affinity identities (A-Identities); the word affinity comes from the experiences, interests and practices, which lead to more than one individual forming "affinity 
groups", even if they are dispersed over a large area or space. According to Gee "the source of this power is not nature or an institution or even other people's discourse and dialogue alone, but an "affinity group" (Gee, 2000 , p. 105). In this way, A-Identities are formed by participating and being part of distinctive social practices, attending events or forums, or even internet-based groups/ activities.

The distinction in this perspective of identity is that an individual needs to actively seek out and try to establish affiliation to an affinity group and hence develop an A-identity; sometimes institutions attempt to create opportunities for employees to form affinity group and gain experiences of personal value with colleagues. While doing so, they develop an "Institutionally sanctioned" A-Identities., and in the process strengthen their I- Identities (Rifkin, 2000; as cited by Gee). Gee is of the opinion that such A-Identities are similar to creating "quality circles", and spread some agency and autonomy to the employees while working on projects This is similar to creating 'quality circles' where workers work on projects as teams as if they are their own 'bosses', without the constant presence or supervision of the actual bosses (Gee, 2000, p. 106).

\section{Research Objective}

The current study aimed to develop an understanding of teacher identities at the tertiary level in Pakistan, by utilizing the Analytic Lens for identity proposed by Gee (2000). The research objective was to examine the factors which contributed in the development of N-Identity, D-Identity, A-Identity and I-Identity, in addition to reconstructing how these identities were manifested through the participant narratives.

\section{Methodology}

The researcher adopted the constructivist stance for this study; the aim was to dig deep into the mental understanding and inner world of the participants, to know their experiences and thought processes as they constructed their personal and professional identities. The study also aimed to contribute to "theoretical extension", which involves "theory engagement as 'transferability' of theory between multiple contexts" (Reeves et al., 2013, p. 1373); it examined patterns of identity development as they appeared across contexts.

\section{Study Population and Sampling}

The target population for this study was identified as the teachers and academics who teach in tertiary level educational institutions in 
Pakistan, both in the public or private sector. It was necessary that the teachers have a minimum of two years' experience in teaching in their organization. The researcher selected six participants on the basis of experience for this study; they were purposively selected to offer a cross section of the teachers of tertiary level institutes of Pakistan. As the distinction between public and private sector organizations and institutes is widely recognized in Pakistan, including the urban setting of the city of Lahore, out of the six participants, one case each from a public sector university and a private sector degree college was taken to provide contrasting viewpoints and experiences of teachers working in such organizations.

Two cases were selected from a semi-government organization which has been autonomous for over a decade and is considered one of the leading organizations with a rich research culture. The cases were compared to examine similarities, disparities and consistencies in teacher experiences or narratives, in the same or similar context or circumstances. A fifth case chosen of a part time teacher, who taught in several organizations on ad-hoc or contractual basis, was assessed to see the distinctions that arise when a fixed organizational culture or context is removed from the factors that influence identity formation. Such exposure to multiple teaching environments or organizations highlighted how the participants, who worked as permanent members of faculty in a certain organization, negotiated and made adjustments to their identities to stay or become a part of one organization.

The sixth case provided a different context, being from another city, hence providing an insight into the basic thinking and professional similarities or differences in how professional think, act and grow in organizations of different cities. Also, the sixth case being a male participant, brought forth striking contrasts, and points of discussion, in how the way of thinking of male professionals may, or may not be, distinct from that of female ones.

Due ethical considerations were kept in mind and the participants were assured of complete anonymity, confidentiality and the right to withdraw from the research at any time; in addition, due care was afforded to safeguarding the interests and identities of the participants (Reeves et al. 2013, p. e1368). The participants were assigned the pseudonyms Atiqa, Gia, Amna, Saima, Faiza and Sarmad, and their quotes are referred with the pseudonyms in the analysis section. Lastly, a meeting schedule was drafted as per their convenience and availability. 


\section{Data Collection}

For this study data triangulation was achieved through the use of life histories, in-depth interviews and field notes record stories, descriptions and interpretation, in addition to connecting data collection and analysis "through iterative reporting and interpretation of findings from all methods utilized" (2013, p. e1370). The in-depth interviews were used to "provide insight into articulating and explaining social everyday life (Reeves et al., 2013, e1369); while life histories extend the knowledge of the researcher beyond the 'now', to create a better understanding of the progression and impact of social processes (ibid.).

The participants were interviewed at the place of their choice over four sessions: the first session was for screening and collecting demographic information, as well observing the work space and dynamics; the second and third session were each an hour and a half long and focused on the life histories and interview protocol developed. The final session was reserved for discussion and themes building based on the transcriptions of the interviews. The participants were given the choice to either respond in their mother language, Urdu or Punjabi, or in English. Permission to record the interviews was taken beforehand, and only audios of the interviews was used in data analysis.

\section{Research Instruments}

The first research instrument, the life history narratives were aimed at collecting teacher stories to better understand the meaning of the experiences and personal journey of becoming teachers. The life histories traced their journey from the beginning of the career to the present-day negotiations and changes, and were supplemented by examples of significant events, factors, people and incidents.

The second source of data collection was the field notes taken by the researcher in the work place of the participants, and, while interviewing. The interview notes described any change in tone, wording, body language and code switching, which was later discussed with the participants for potential implications.

The semi structured interviews were the third mode of data collection for this study, which were based on the Analytic Lens for Identity, presented by James Gee (2000); they focused on the four aspects of identity; N-Identity, D-Identity, I-Identity and A-Identity. Three questions were based on the self-recognition of N-Identity, recognition from others and teacher emulation as an influence on N-Identity. Four 
questions were about D-Identity, asking about the nature and effect of DIdentity; and the effects of institutionally promoted D-Identities, and whether the D-Identity is an 'ascription' or 'achievement'. The next five questions relate to I-Identity, covering such aspects as identification with the institutional values, assuming I-Identity as a 'calling' or an 'imposition' and the effects on practice. The last three questions address the A-Identity, the nature of participation, institutionally sanctioned affinity groups, scope for future participation etc.

Table 2

Questions Based on James Gee's Lens for Identity

\section{N- Identity}

1. Were you a born teacher? (Does it come naturally to you or did you learn to become one?)

2. Did others draw your attention to your ability to teach? Or did you recognize it yourself?

3. Do you emulate your own teacher's style?

\section{D-Identity}

1. Do you think you have a certain quality or trait that makes you distinct as a teacher? May be a quality you think you have, or others tell you that you have.

2. Inherent in nature or is it cultivated?

3. What is the effect of this trait on your self-image as a teacher?

4. Are there any institutionally sanctioned traits or some quality that holds more value to the administration or the colleagues? Are you encouraged to adopt them?

\section{I-Identity}

1. What is the impact of being a teacher in your institution?

2. Are you comfortable with the administrative demands and job specifications at your workplace?

3. How do you handle unnecessary or conflicted demands from the administration?

4. Is there any inner conflict or anger due to such demands? How do you handle them?

5. What are the effects of organizational culture and role expectations on class room practice (use of methodologies)?

\section{A-Identity}

1. Are you a part of a group or forum of teachers which you like to interact with because of a similar interest? Describe your experience with them? What do like or enjoy the most about it?

2. Has anyone ever influenced or pressured you to become a part of such a group? Your family/ Organization? How did you react?

3. Do you think such experiences help you as a teacher? Would you like to participate in such forums in the future? 


\section{Data Analysis}

The researcher transcribed the extensive recordings of both the life history interviews and the semi structured interviews based on the James Gee Analytic Lens for Identity; the data was translated to English when required. The transcriptions were then shown to the participants in the final meeting to discuss their authenticity, and the findings about the identities of the participants were discussed with them. The data was analyzed using the Miles and Huberman's framework for data analysis (1994); the framework uses three kinds of activities to decode data: data reduction, data display and conclusion drawing (Miles \& Huberman, 1994).

In order to completely understand the four perspectives of identity as applied to the six participants, the researcher used constant comparative analysis (or cross-case analysis), where the data was studied repeatedly across participants to highlight commonalities and similarities with respect to N-Identity, D-Identity, I-Identity and A-Identity, as presented by Gee (2000). The researcher also merged the data collected from the three instruments to develop a holistic understanding of the four sources of identities.

\section{Results and Conclusions}

\section{Gee's Four Perspectives of Identity}

N-Identity. According to the narratives and interview data of the participants of this study, four of the six participants acknowledged, and were aware of, their Nature or N- Identities. Amna and Saima believe that they have the inherent ability to be teachers. Amna was not trained in teaching methodologies prior to her appointment as a teacher, but she was surprised to find out that she had the talent to make students understand and learn, although she did not know how she knew exactly what to do. In the case of Saima, she said that she had the inborn quality to impart knowledge; this was recognized by her seniors, and also her students, who appreciate her as a teacher.

Faiza on the other hand had no plans to join teaching as a profession and still feels that she does not possess the nature or temperament for it. But she had settled into her role as teacher over time and built a rapport with her boss and students, and now revels in her role as a teacher. Atiqa too felt she was not born to be a teacher but says her drive to make others understand a point is what makes her a good teacher. Hence a part of her nature has contributed to her successfully 
adopting the role of a teacher, but as a whole, teaching was not her career of choice.

Gia was a unique case, because she mentally understood her ability and natural potential to be a teacher; a potential recognized by her peers, students and teachers, who told her she is born to be a teacher. Personally, Gia is still in denial of her identity as a teacher and does not consider herself a professional in teaching. She said it is a hobby or a passion but not an essential part of her nature: 'I do recognize that maybe I have that quality and ability. I may not want to acknowledge it but thank God I have some ability in it'.

In Sarmad's narrative, there are some similarities when it comes to the professional and technical aspects of the profession; but many differences in the personal and collegial aspects of identity. Sarmad never aspired to be a teacher of English; his interest lies in the fields of Mathematics and the sciences, and the advancements therein. Personal events and disappointments in the academic field led him to opt for a career as a teacher for financial reasons and expediency. His journey since then, according to him, has been uneventful and quite average.

Sarmad did not recognize any N-Identity and considers himself an average teacher, who has learnt to cope as a strategic compliance. He did not identify or feel pride in being a part of his organization or professional community. He did consider his talent to induce students to think critically and out of the box, as his distinctive trait as a teacher; but considers it an inherent part of his nature and says he has adapted his personal trait to fit in with his responsibilities as a teacher.

The results about $\mathrm{N}$-identity were confirmed by the data from the fieldnotes. Amna, Saima and Gia displayed ease of deportment and a relaxed body language when talking about their inherent abilities as teachers, and accepting this identity. Faiza, Sarmad and Atiqa displayed tension when talking about their N-Identities; Sarmad's tone was especially noticeable during the interviews, he resorted to repeated throat clearing. Fidgeting and shifting in the chair, all through talking about NIdentity.

On the whole, the researcher found out that four of the six participants were aware of their natural aptitude as teachers, although only three of them accepted it openly. The other three participants had personal doubts and reservations about N-Identity, of which two reluctantly accepted that they may have the inherent skill to become good teachers. One participant was especially denying any $\mathrm{N}$-identity 
and insisted he did not choose this profession. The consolidated outcomes about N-Identity have been presented in the table below.

Table 4

N-Identity: Key aspects for the Participants

\begin{tabular}{ll}
\hline Key aspects of N- Identity & Number of participants \\
\hline 1. Awareness of natural aptitude as a teacher & 4 \\
2. Settled into N-Identity over time: required effort & 3 \\
3. Open acceptance of N- identity & 3 \\
4. Personal doubts about N- Identity & 3 \\
5. Partial acceptance: Nature to make others understand & 2 \\
and/or think critically & 2 \\
6. Career choice based on N-Identity & 1 \\
7. Denial of N-Identity &
\end{tabular}

I-Identity. The second perspective of Identity, the Institutional perspective or I-Identity featured prominently in the stories of five of the six participants. There was a positive association and feeling of pride in the participants in holding a position in their respective organizations and institutions. This pride resided in the prestige and respect generated by association with the institution. In Gia' $s$ case the pride came from beginning her career as a teacher at the tertiary level and teaching master's students.

Amna feels that there was a different reaction from people when they realized that she taught in a degree college. Her family strongly opposed whenever she discussed leaving her current job to teach at the primary level for experience. She took pride in her current designation and was mostly comfortable with the responsibilities and demands that come with the position. When she did feel conflict with any institutional policies, she tried to find a middle ground, where she fulfilled institutional protocol, and at the same time followed her personal convictions. She considered only parts of her position as an 'imposition' and agreed with the rest.

For Faiza, the skepticism of her family and social circle affected how she initially perceived her status as a member of her institution, but with time she had set her own parameters and now she was proud of her institution's standing in the academic world. She reflected: 'There is a lot of growth here. And they (academia) immediately know why I am here. That is the difference'. 
She accepted that there were challenges and difficulties in adopting her current position, but she took them in her stride as she felt that they were normal in any such institution.

Atiqa had to say that, 'Just being a lecturer is something that gives me a good feeling...But outsiders see us with respect for being teachers of college students. The respect and reaction of people visibly changes upon knowing our profession'.

Saimawas even more emphatic about the role of her institution in the construction of her identity, saying: 'Whatever I am is because of the institution and because of the trainings, whatever I am teaching it reflects my training'. She further said that she could not envision herself teaching anywhere other than her current institution and felt loyalty towards it.

Sarmad talked of his initial adjustments as a necessary part of the job, for he was aware of the mind-set of the administration and other colleagues; he faced derision and esteem issues as a male teacher of English. The motivation to adjust or comply with institutional or administrative demands came not from an inner need to fit in or identify with the institution and the work environment; rather the knowledge that there was no other way, and any resistance would lead to eviction from the job. This was where he strategically complied and chose the part of least resistance.

The field notes displayed the pride Gia took in her I- Identity, as her eyes shone and her body language became eager and alert when she talked about being a tertiary level teacher. Amna was still undecided, as she continued to frown and play with her pen when talking her family's opposition to her place of work. Faiza showed a determined demeanor throughout, as if she willed herself to adapt to her changed identity. Atiqa and Saima were very positive in their body language, while Sarmad showed resignation and lack of interest. He sat back with splayed legs and kept fidgeting with the corner of the notes placed in the next chair.

Overall, four of the six participants were aware and in acceptance of their I-Identity, whereas only three of them took pride in it, which was mostly when others perceived them positively. The conflict in I-Identity arose mainly due to a clash with personal beliefs, and a feeling of imposition. Only one case showed strategic compliance which is an indicator of alienation from I-Identity. The consolidated results received from the sic participants are as follows: 
Table 5

I-Identity: Key aspects and factors contributing to I-Identity

\begin{tabular}{ll}
\hline Key aspects of I-Identity & Number of participants \\
\hline 1. Awareness and acceptance of I-Identity (Calling) & 4 \\
2. Personal pride in beginning at a tertiary level institution & 3 \\
3. I-Identity due to perception of others & 3 \\
4. Conflict in I-Identity: & 2 \\
a. Imposition & 2 \\
b. Clash with personal beliefs & 2 \\
c. Dissatisfaction of family with institution & 1 \\
5. Alienation from I-Identity: strategic compliance & \\
\hline
\end{tabular}

D-Identity. D-Identity or the discursive perspective is the third lens for examining identity. D- Identity views individual traits as the source of identity where individuals may or may not seek or develop such traits as a defining aspect of their personal and professional identities. The stories of the participants for this study show that D-Identities are indeed important perspectives in how they view their persons as professional teachers. In the case of Amna the discursive identity was'achieved' or developed, where she felt that she must be accessible and always helpful to her students. She consciously strived for this trait, even though at times her peers and administration pointed out that she must monitor this trait. Also, she says:

'I sometimes feel burdened by it, because sometimes I don't have the time for interruptions, maybe I am doing some administrative work and a student comes asking for advice or explanation to something...but I never resent it and do not feel it as a burden'.

Saima felt that she was inherently friendly and emphatic, and accorded the same amount of respect and attention to her students which she would have liked for her. But she also cultivated the trait of patience in handling student affairs and considered it an essential trait for all teachers and educational management. She also said that her organization and leadership instigated their teachers to be helpful and cooperative towards all students, which all her peers too practiced. Hence, for Saima her traits were a mix of 'achievement' and inherent characteristics. The reason she adhered to these traits in her practice was that they were also approved by her institution and enhance her self-image as a representative of her institution. She displayed a very enthusiastic and positive body language when talking about this, leaning forward in her chair with shining eyes when speaking. 
Faiza who works at the same institution, on the other hand, felt that a healthy 'sense of humor' was one of her strengths. She felt it was an inherent part of her personality and she actively employed it to facilitate a desired response in the people she interacted with professionally. Whether her students felt that a sense of humor was one of her strong suits, was still unknown to her. But she said that she used it to break the ice. In this sense her D-Identity was ascribed, not achieved through active manipulation, although her body language showed that she was in complete accord with this ascription, feeling no resentment with it.

Atiqa said out right that she had an ascribed D-Identity, which she had come to recognize in herself through experience. Her D-Identity was perseverance in teaching, as she says, "if I get behind a point I explain it fully. If I intend to do something I finish it, and unless I finish it I don't remain at peace. It is positive quality for my students because if I see some lack in my students I do my utmost to make them understand'. Also, she said that her administration encouraged and always expected the English teachers to be civilized and well behaved; even in anger, they were expected to control their behavior especially their language. This trait was something she has cultivated to create a positive self-image professionally. The field notes taken also noted how she was forceful and her tone rose when she was talking about her image-building efforts.

Gia had two such traits that define her as a teacher; one was ascribed and the second achieved. As she explained: 'I don't think I have a quality, but others recognize, it's that I demand discipline. I don't think I demand discipline...but it is something that has come to my knowledge. Another thing which my experience has taught me is that if you are truly sincere in teaching, only then can the students be equally sincere in their learning'. Her self-image is enhanced when she associated these traits with her professional self. She seemed very passionate and vocal when talking about her traits.

Sarmad, on the other hand, refused to acknowledge that he had any kind of D-Identity; he did not think the discourse or interactions of others had in any way help in contributing to his identity. He believed that such discourse would only be negative in his case; others did not enhance or appreciate any of his professional traits as a professional teacher. Nor had he any keen interest in developing such identity. His body language displayed the same features, as when talking about IIdentity. 
The D-Identities in the case of three participants reflected onto their I-Identities. Four of the six participants shared that their D- Identity was ascribed and not personally recognized. Three of them actively cultivated and recruited qualities and traits in their discourse and interactions which became a part of their D-Identities, while the other three adhered to institutionally sanctioned ones, which they knew would garner them a good repute within their institutions. One case offered contrast and did not acknowledge or actively recruit a D-Identity. The complied results are shown in the table below:

Table 6

D-Identity: Key features and contributing factors

\begin{tabular}{ll}
\hline Key aspects of D-Identity & Number of participants \\
\hline 1. Imposed/ Ascribed D-Identity & 4 \\
2. Actively recruited D-Identity & 3 \\
3. Institutionally sanctioned D-Identity & 3 \\
4. Institutionally instigated D-Identity & 2 \\
5. Rejection of D-Identity & 1 \\
\hline
\end{tabular}

A-Identity. This is the most neglected perspective in the construction of identities for the participants of this study. There is not one participant who is part of an affinity group, forum or group who bears allegiance and participates in activities of common interests or concern, especially outside the institution. Amna confessed to being part of some online forums related to teaching, but she was a silent member, only reading what others write and learning through that practice. She shared that she was sometimes successful in achieving the results she aimed for andheld the opinion that such forums were a good way to learn. She was open to becoming a more active member if she ever got a chance in the future.

Faiza and Saimasaid that they were encouraged to reflect with their institutional peers and sometimes did find the opportunity to sit and collaborate, but the load of administrative work and time constraints made it quite impossible to do so often, or on a regular basis. The peer interactions within the institution were quite positive and helpful but not significant enough to be an integral part of teacher identities. Saima did feel that online interaction in such forums and communities was better and more suited to her needs, as there would be no time regulations necessary for participation.

Gia also was a not a part of any group or community, but she had some colleagues and friends with whom she connected whenever there 
was need for advice or collaboration. There were no set formal or informal meetings, but they shared advice, new knowledge and experiences whenever they met; she does however feel that, 'I do think such meetings help with the new ways of teaching, gaining the new perspectives of doing things'.

Atiqa confessed that she was enjoying the enriching experience of interacting with the 'institutionally sanctioned' affinity group of her work colleagues. The administration encouraged the teachers of the English department to stay in their staffroom and spend maximum with their colleagues. There was an atmosphere of sharing, learning and collaboration; the teachers did not hold back or hide any new or useful information they got. She explained:

I share everything with my colleagues, our common interests, problems and issues, help each other with lectures, student behavioral issues, strategies to teach weak students; I sometimes ask my colleagues how they would respond to a situation involving some weak students. Sometimes a new point or method for teaching a certain lesson is shared with the colleagues, and we share these things very freely'.

Atiqa felt that $50 \%$ of what she knew about teaching came from such interactions and talking to an experienced colleague for a short time was better than reading a dozen books. She said that what was read in books and research was quite different from the actual practice; hence, sharing amongst colleague was a more relevant way to learn and improve.

Sarmad did not personally identify with other teachers of English, as most of them are women, and/or were passionate or interested in their profession. He did not identify or feel pride in being a part of his professional community; no A- Identity was evident from within his narrative or interview responses.

Overall, the participants of this study acknowledged the benefits of sharing experience within a community of people with common interests, whether online or face to face. But such opportunities are restricted for the teachers of tertiary education in Pakistan due to lack of time and heavy workloads.

All the participants showed surprise when talking about their AIdentity; they had not previously given much thought, especially outside of their work context. They showed some enthusiasm when talking about institutionally sanctioned or encouraged A-Identity, with only two even being aware or in favour of there being need for such an identity. Only 
one participant displayed any inclination towards actively seeking or wanting to be part of an affinity group online. One extreme case even rejected the role of affinity groups towards the construction of one's identity, as showed in the table below:

Table 7

A-Identity: Key aspects for the Participants

\begin{tabular}{lc}
\hline Key aspects of A-Identity & Number of participants \\
\hline 1. Institutionally sanctioned/encouraged A-Identity & 3 \\
2. Acknowledgement of A-Identity through online & 2 \\
forums & 2 \\
3. Awareness for need of A-Identity & 1 \\
4. Personally-sought affinity groups & 1 \\
5. Rejection of A-Identity & \\
\hline
\end{tabular}

\section{Discussion}

Considering the above analysis of the participant identity processes and the features and characteristics of the four perspectives of identity as presented by Gee, it became evident that the journeys and individualized stories of identity formation are highly contextualized and intensely subjective, with strong links to one's past. This is endorsed by the work of Flores and Day (2006), who have linked identity to past influences and personal biography. It was observed that past influences were crucial in shaping the N-Identities of the participants of this study, and the support and approval (disapproval, in some cases) of the significant people in the past, contributed to a strong sense, or lack thereof, of N-Identity.

What was also shown in the narratives was that the participants were not aware of the changes in identity at that time, but reflection and recounting the incidents and process made them become aware of, and appreciate, the changes and growth in their sense of self. This has been to dominant discourse in international research (Graham and Phelps, 2003), and reinforces the practice of making novice teachers reflect on their identity development makes them better practitioners.

Another aspect which came to light through participant narratives was the defining role of teaching practices and the work culture. This has been endorsed by the research of Davis, Sumara and Luce-Kapler (2000) who presented the view that teacher identity formation follows the rule of "we become what we do" (p. 4). Three of the six participants showed marked acceptance of the teaching practices within institutions which contributed to their I-Identity; conversely the 
other three participants were in conflict with their institutionally imposed identities. These three participants merely endured their institutional practices, as they were at odds with the individuals' personal beliefs about teaching and their professional identity. To support teacher identities, policy makers and administrators may work on transforming the work space and culture into more supportive learning environments, where individuals experience a sense of belonging as proposed by Weeks (1990).

The imposition of I-Identity also affected the discursive identity, where the individual traits become a source of identity, of the participants. In cases where the participants were unwilling to agree with institutional policies and practices, their D-Identify felt imposed or ascribed, not actively recruited; this became evident in the interviews of four of the six participants. In such cases, the participants felt they became mere service providers or paid employees of the institution, and not active contributors to both the organization and the profession.

This phenomenon has been mentioned in the research by Dillabough (1999), whereby it is mentioned that if less importance and regard is given to the private spheres and beliefs of the teachers, their sense of identity and commitment to the profession is seriously subjugated. The participants mentioned that they felt like mere puppets and service providers in their institutions and felt no sense of personal accomplishment or reward. The accounts of two participants mentioned the use 'strategic compliance' to avoid conflict and negative forces in the organization, which is mentioned and reinforced by the research of Flores and Day (2006, p. 229).

The findings of this study are significant in bringing forth teacher perspectives and voices, and highlighting aspects within identity formation which may contribute to research and studies on teacher attrition and commitment to the profession. As stated by Roulston, Legette, and Womack (2005), 33\% of professional teachers quit the profession in the first three years; this may point to a link with conflicted, or imposed, discursive and institutional identities. A deeper investigation into these perspectives of identity, and of the factors contributing to job satisfaction, may benefit policy makers and administrators, in supporting the transition of teacher identities within their institutions.

One reason for attrition which came to light was that the novice teachers do not realize the demands and requirements of the profession and may have an idealistic or cursory knowledge of their responsibilities 
and practices as professional teachers. This is also supported by the work of Murshidi, Konting, Elias, and Fooi (2006), who say that the disparity in the expectation and reality may come across as a reality shock and may put off many teachers.

On the other hand, a study of identity narratives may better inform teacher trainers and professional training institutes about the misconception and/or idealistic portrayal of the job of a teacher. This information may then be used to design or modify existing teacher training programs or introduce more appropriate trainings for inductees to the profession, to mitigate the initial shock. It can safely be said that research teacher identity formation processes in one's context and environment, thus becomes invaluable. Moreover, such voices and narratives may be continuously collected from teachers working at different levels, in different cities and also in schools or universities catering to only one gender. 


\section{References}

Anhorn, R. (2008). The profession that eats its young. Delta Kappa Gamma Bulletin, 74(3), 15-26.

Beijaard, D. (1995). Teachers' prior experiences and actual perceptions of professional identity. Teachers and Teaching: Theory and Practice, 1(2), 281-294.

Bergner, R. M., \& Holmes, J. R. (2000). Self-concepts and self-concept change: A status dynamic approach. Psychotherapy, 37(1), 36-44.

Bullough Jr, R. V. (1991). Exploring personal teaching metaphors in preservice teacher education. Journal of Teacher Education, 42(1), 43-51.

Cobold, C. (2007). Induction for Teacher Retention: A Missing Link in Teacher Education Policy in Ghana. Post-Script (1444-383X), 8(1).

Davis, Brent, Sumara, D., \& Luce-Kapler, R. (2000). Engaging minds: Learning and teaching in a complex world. Mahwah, NJ: Erlbaum.

Dillabough, J. A. (1999). Gender politics and conceptions of the modern teacher: Women, identity and professionalism. British Journal of Sociology, 20, 373-394.

Day, C., Stobart, G., Sammons, P., \& Kington, A. (2006). Variations in the work and lives of teachers: relative and relational effectiveness. Teachers and teaching, 12(2), 169-192.

Featherstone, H. (1993). Learning from the first years of classroom teaching: The journey in, the journey out. Teachers College Record, 95(1), 93-112.

Flores, M. A., \& Day, C. (2006). Contexts which shape and reshape new teachers' identities: A multi-perspective study. Teaching and Teacher Education, 22(2), 219-232.

Freese, A. R. (2006). Reframing one's teaching: Discovering our teacher selves through reflection and inquiry. Teaching and Teacher Education, 22(1), 100-119. 
Gecas, V. (1985). Self-concept. In A. Kuper, \& J. Kuper (Eds.), The social science encyclopedia (pp. 739-741). London: Routledge.

Gee, J. P. (2000). Chapter 3: Identity as an analytic lens for research in education. Review of Research in Education, 25(1), 99-125.

Graham, A. \& Phelps, R. (2003). 'Being a teacher': Developing teacher identity and enhancing practice through metacognitive and reflective learning processes. The Australian Journal of Teacher Education, $27(2), 11-24$.

Hauge, T. E. (2000). Student teachers' struggle in becoming professionals: Hopes and dilemmas in teacher education. In C. Day, A. Fernandez, T. E. Hauge, \& J. Moller (Eds.), The life and work of teachers. International perspectives in changing times (pp. 159172). London: Falmer Press.

Hill, L. A. (2004). New manager development for the 21st century. Academy of Management Perspectives, 18(3), 121-126.

Howe, E. R. (2006). Exemplary teacher induction: An international review. Educational Philosophy and Theory, 38(3), 287-297.

Kerby, A.P. (1991). Narrative and the Self. Bloomington: Indiana University Press.

Lundeen, C. A. (2004). Teacher development: The struggle of beginning teachers in creating moral (caring) classroom environments. Early Child Development and Care, 174(6), 549-564.

Melnick, S. A. \& Meister, D. G. (2008). A comparison of beginning and experienced teachers' concerns. Educational Research Quarterly, $31(3), 39-56$.

Miles, M.B. and Huberman, A.M., (1994). Qualitative data analysis. Thousand Oaks, CA: Sage.

Murshidi, R., Konting, M. M., Elias, H., Fooi, F. S. (2006). Sense of efficacy among beginning teachers in Sarawak. Teaching Education, 17(3), 265-275.

Nias, J. (1989) Teaching and the self. In M.L. Holly \& C.S. Mcloughlin (eds.), Perspectives on teacher professional development, London: The Falmer Press, pp. 155-173. 
Olsen, B. (2015). Teaching what they learn, learning what they live: How teachers' personal histories shape their professional development. Routledge.

https://books.google.com.pk/books?hl=en\&lr=\&id=swjvCgAAQBAJ\&oi $=$ fnd\&pg $=$ PP $1 \&$ ots $=$ Tr_CAP-1UO\&sig $=q$ GdWU5Q-

VEgJS1qxomEQfgcvOyE\&redir_esc $=\mathrm{y} \# \mathrm{v}=$ onepage $\& \mathrm{q} \& \mathrm{f}=$ false

Reeves, S., Kuper, A. \& Hodges, B.D. (2008). Qualitative research methodologies: ethnography; BMJ (2008);337:a1020. doi: 10.1136/bmj.a1020

Reeves, S., Peller, J., Goldman, J., \& Kitto, S. (2013). Ethnography in qualitative educational research: AMEE Guide No. 80. Medical Teacher, 35(8), e1365-e1379.

Roulston, K., Legette, R., \& Womack, S. T. (2005). Beginning music teachers' perceptions of the transition from university to teaching in schools. Music Education Research, 7(1), 59- 82.

Sachs, J. (2005). Teacher education and the development of professional identity: Learning to be a teacher. In P. Denicolo \& M. Kompf (Eds.), Connecting policy and practice: Challenges for teaching and learning in schools and universities (pp. 5-21). Oxford: Routledge.

Street, C. (2004). Examining learning to teach through a social lens: How mentors guide newcomers into a professional community of learners. Teacher Education Quarterly, 31(2), 7-24.

Volkmann, M. J., \& Anderson, M. A. (1998). Creating professional identity: Dilemmas and metaphors of a first-year chemistry teacher. Science Education, 82(3), 293-310. 
Weeks, J. (1990). The value of difference. In J. Rutherford (Ed.), Identity: Community, Culture, Difference. London: Lawrence and Wishart.

\section{Citation of this Article:}

Moghal, S., Kazi, A.S., \& Aziz, F. (2019). Employing James Gee's analytic lens for identity to investigate teacher identity development.Pakistan Journal of Education, 36(3), 119-143.

DOI: $10.30971 /$ pje.v36i3.1083.g201

To link this article: http://dx.doi.org/10.30971/pje.v36i3.1083 